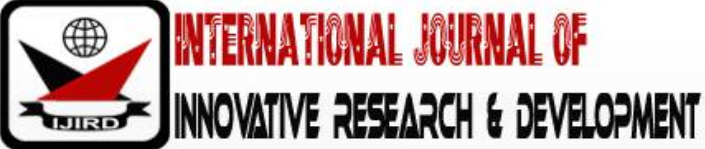

ISSN 2278 - 0211 (Online)

\section{Morphometric Measurements of the Maxillary Sinus Based on Cone Beam Computed Tomography in a Selected Kenyan Population}

\begin{tabular}{c} 
Omar A. Omar \\
General Dental Practitioner, Nakuru Level 5 Hospital. Kenya \\
Nicholas Gichu \\
Consultant Paediatric Dentist, Nakuru Level 5 Hospital, Kenya \\
Tom O. Ochola \\
Senior Lecturer, Department of Oral and Maxillofacial Surgery, Radiology and Pathology School of \\
Dental Sciences, College of Health Sciences, University of Nairobi, Kenya \\
Regina J. Mutave \\
Senior Lecturer, Department of Community and Preventive Dentistry, and Periodontology and Dean, \\
School of Dental Sciences, College of Health Sciences, University of Nairobi, Kenya \\
\hline
\end{tabular}

\begin{abstract}
:
Objective: To assess the maxillary antrum (sinus) volume, dimensions, and to establish the sinus floor relation ship to posterior maxillary teeth roots and the prevalence of septation using Cone beam Computed Tomogram (CBCT) scans in a selected Kenyan population.

Study design: A descriptive, cross-sectional retrospective study.

Study Area: The study was carried out in Nairobi, the capital city of Kenya, a cosmopolitan city that has the largest referral hospital in Kenya.

Study material: Cone beam Computed Tomogram (CBCT) scans of the midface region obtained with permission from a private maxillofacial imaging centre in Nairobi. The study population was determined using convenient sampling method, obtaining 55 scans of the Maxillary sinus.

Results: Fifty-five scans were analyzed with 20(36.4\%) belonging to males and 35(63.6\%) being scans of females. The mean septum height was $4.5 \mathrm{~mm} \pm 1.9 \mathrm{~mm}$ and the mean exostosis height was $4.2 \mathrm{~mm} \pm 2.2 \mathrm{~mm}$. The closest root apex to the antral floor was the mesiobuccal root apex of the second permanent molar: $2.2 \mathrm{~mm} \pm 1.5 \mathrm{~mm}$.

There was a statistically significant difference between gender and the anteroposterior dimension of the sinusp $=0.02$,

The mean sinus volume was larger in males, $13980.4 \pm 5024.4 \mathrm{~mm}^{3}(13.9 \mathrm{ml} \pm 5.0 \mathrm{ml})$ than in females, $10,885 \pm 3305.6 \mathrm{~mm}^{3}$ $(10.8 \mathrm{ml} \pm 3.3 \mathrm{ml})$. The difference was not statistically significant.

Conclusion: There is variation of the maxillary sinus size, within the same individual and among different individuals, thereby emphasizing the need for a complete imaging in treatment planning in the para-antral region.

Due to the increased use of implants in dentistry, CBCT imaging as part of the diagnostic pre-implant workup and sinus analysis is crucial so as to avoid complications during surgery in the para-antral region
\end{abstract}

Keywords: Maxillary sinus, Antrum, Cone Beam Computed Tomography, Apicoantral distance, Kenyan population, Antral septum

\section{Introduction}

The maxillary sinus, also known as the antrum of Highmore, is the largest of the paranasal air sinuses in the human skull. They are a pair of bilateral, pyramidal pneumatic spaces located in the body of the maxilla.(Sandring, S \& Berkovitz, Barry B, 2004). It is the earliest of the sinuses to develop as a diverticulum of the lateral nasal wall into the maxilla and is filled with fluid at birth ("Paranasal Sinus Anatomy," 2016). The sinus has its base towards the lateral nasal wall with its apex extending into the zygomatic process of the maxilla.(Orhan et al., 2013; Shahidi, Zamiri, Momeni Danaei, Salehi, \& Hamedani, 2016) 


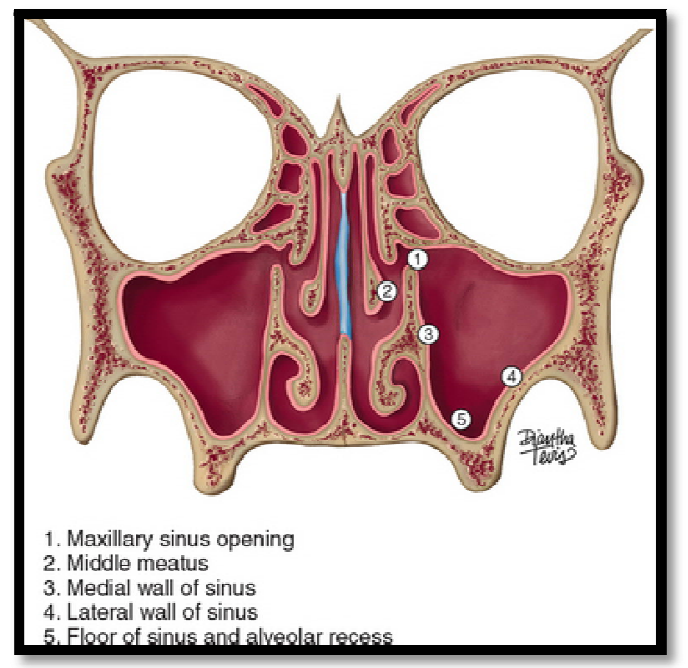

Figure 1: Schematic Illustration Of The Maxillary Antrum

The paranasal sinuses are centred around the nasal cavity because of their embryonic origin from the lateral nasal cavity walls, thus also sharing the same epithelium and opening into it. They open into it allowing equilibration of air and movement of mucus.via a mucociliary system.("Paranasal Sinus Anatomy," 2016; Sadler, T W, 2000)

The paranasal sinuses together with the turbinates play a role in humidification and heating of inspired air, adding resonance to the voice, and shaping the facial contours during their differential enlargement over the years and reducing the weight of the skull. It is also thought to be of importance in facial trauma acting as a 'crumple zone' cushioning traumatic forces to the midface, thereby protecting the brain.("Paranasal Sinus Anatomy," 2016; Sadler, T W, 2000)

Implications of the maxillary sinus in dentistry include, but are not limited to, maxillary sinusitis of dental origin, which may be a result of; the spread of infection from a periapical or periodontal abscess. Overextension of dental materials such as endodontic files, endodontic irrigants, endodontic sealer cement and obturating materials like GuttaPercha $^{\mathrm{TM}}$ points, which could perforate the floor especially in roots adjacent to the floor of the sinus. (Hauman, Chandler, \& Tong, 2002).The occurrence of oroantral fistula can be caused by implants and extraction of teeth with roots located in the sinus and tear of the Schneiderian membrane during sinus lift. Pain from maxillary sinusitis may be mistaken with that of pulpal origin.

As for the use of CBCT in this study, it provides a 3-dimensional view of the structure being scanned, hence of more spatial accuracy than the conventional 2-dimensional radiograph.

3-D volumetric data generated by software algorithms are used to construct primary reconstruction images in 3 orthogonal planes (axial, sagittal and coronal) and a 3-D animation reconstruct

There have been studies looking individually at sinus dimensions and volume, presence of septation, Apicoantral relationship of posterior maxillary teeth to the antral floor, but none with a collective analysis of the aforementioned variables in the same population.

However, nonsignificant findings for the measured widths and height of the maxillary segments and the "standard" dimensions indicated in textbooks, standard being a relative term, are not directly applicable to different populations.

Locally in Kenya, there was study carried out in the Kenyan population using standard occipitomental radiographs, assessing the mean height and width of the sinus, which was limited to 2- dimensional spatial analysis and therefore of limited value in volumetric analysis of the sinus (Ochola S., Muasya M, Hassanali J, \& Guthua S.W, 2001).

Data on maxillary sinus morphology and multidimensional measurements of the MS in the Kenyan population is unavailable and scarce within the African continent. Furthermore, most studies in this field done on different populations(Eberhardt, Torabinejad, \& Christiansen, 1992; Jun et al., 2005; Kilic, Kamburoglu, Yuksel, \& Ozen, 2010; Neugebauer et al., 2010) have shown significant differences and anatomical variation across different populations.

Among the advantages of CBCT in maxillofacial practice over conventional CT includes X-ray beam limitation to the area of interest, image accuracy of CBCT scans; the voxel resolution in CBCT are isotropic and anisotropic in conventional $\mathrm{CT}$, the scan time is much rapid than CT (10-70 seconds) resulting in less motion artefacts due to patient movement, dose reduction from the dosage of traditional fan-beam CT to the effective dose of that of film-based periapical view.(Scarfe William C., Farman Allan G., \& Sukovic Predag, n.d.)CBCT particularly has become popular and a frequently used imaging modality to assist dentists and other healthcare professionals as part of diagnostic workup("Basic Principles of Cone Beam Computed Tomography," n.d.).

In a study done in a Korean population assessing sinus volume according to chronological age and gender, they found that the MS development continued until the $3^{\text {rd }}$ decade in males and until the $2^{\text {nd }}$ decade in females.(Jun et al., 2005)

Another important morphological feature of the sinus is the maxillary septum also known as Underwood's Septum, a fin-shaped bony projection from the inner surface of the sinus(Underwood, 1910). It can be classified according to the wall involved: anterior(Krennmair, Ulm, Lugmayr, \& Solar, 1999; Ulm, Solar, Krennmair, Matejka, \& Watzek, 1995), middle(Kim et al., 2006; Velásquez-Plata, Hovey, Peach, \& Alder, 2002)and posterior(Underwood, 1910). Another classification is primary and secondary septa. Primary septa (Underwood's septa) form occurs as a result of the sinking of 
the floor of the sinus along with the eruption of teeth during the development of the maxilla. Secondary septa are as a result of irregular pneumatisation of the sinus after the loss of posterior maxillary teeth. (Krennmair et al., 1999)The septa divide the maxillary sinus into several parts or compartments, and this is clinically relevant during sinus lift surgery where septa located at or near the sinus floor are implicated in perforation of the Schneiderian membrane during the procedure. (Al-Dajani, 2016) Therefore, this may necessitate septa removal before or during sinus augmentation, that is if the procedure cannot circumvent the septa. The maxillary sinus septa has been known to cause Schneiderian membrane perforation in sinus lift procedures.(Al-Dajani, 2016; Koymen et al., 2009)

A feature that may present or be seen on scans is bony exostoses. An exostosis is a rounded bony projection that may be located on the sinus walls, while a bony septumis pointed.

(Neugebauer et al., 2010) analyzed 1,029 consecutive patients using CBCT scans to determine the prevalence of septa, concerning age, sex or side; either right or left, and the number of septa, positions and their height if present. Septa were found in $47 \%$ of patients. Most patients with septa had one septum in one sinus (24.6\%). The septa variation shows that the septum is a very variant feature of the sinus that is not always present in the sinus or even in both sinuses of one person. The septa positions were most in the molar area with 625 septa and the least in the canine area (5 septa). Therefore, due to the significance of the probability of septa presence, it is justified to do pre-operation imaging of the sinus before sinus operations such as sinus lift and augmentation. (Neugebauer et al., 2010)

There is a correlation between the maxillary posterior teeth roots and the floor of the sinus. With age, the height of the floor of the sinus to the teeth roots decreases, and increased incidence of teeth roots being in the sinus in older subjects. The possible presence of root in the sinus is particularly important in implant treatment planning of the posterior maxilla in edentulous patients. (Krennmair et al., 1999)

A study on the prevalence of the maxillary septa by focused on children and adult populations: dentate, partially dentate and edentulous patients (Koymen et al., 2009; Orhan et al., 2013). The study was a retrospective analysis of 554 CBCT scans of sinuses. The prevalence, morphology and location of the septa were analysed in axial, sagittal, crosssectional and 3-D views. Measurement of the angle between the direction of the septum and the median palatine suture with the height of the septum was done. The septa prevalence was $58 \%$ with a greaterprevalence in the middle region $(69.1 \%)$ than in the anterior or posterior. This further reiterates that maxillary sinus imaging is essential and should be part of the diagnostic aids in any sinus surgical procedure and also to avoid potential surgical complications. (Koymen et al., 2009; Orhan et al., 2013)

Complications that arise due to failure to use detailed accurate radiography or imaging modality in any surgical procedure is tantamount to malpractice by the practitioner and exposing him/ her to litigation. Therefore, this study will be important in providing morphometric data pertaining to the maxillary sinus in Kenyans. The data generated will also be far-reaching in enhancing diagnostic and management quality especially in implant surgery and placement.

\section{Materials and Methods}

\subsection{Study Design}

It was a descriptive, cross-sectional retrospective study. The study area was located in Nairobi a cosmopolitan city. It is the headquarters of the Central government with most major economic, administrative and cultural centres and among the fastest growing in Kenya. It is also home to the country's largest referral hospital, Kenyatta National Hospital, and most healthcare facilities are located here. Thus, Kenyans from every part come to Nairobi for medical treatment and referral from peripheral primary health care centres, making it a prime sampling pool of the Kenyan population.

The material for the study was obtained from Dental and Maxillofacial Imaging Centre (DAMC), a private imaging centre located in Nairobi. The study utilised CBCT scans obtained from the records of patients who had been previously referred to that facility.

A convenient sampling method was used and due to lack of local research with prevalence, prevalence was assumed at $50 \%$, at a confidence interval of $95 \%$ and using Fisher's sampling formula, the calculated sample size for a population $<1,000$ was a minimum sample size of 132 scans. However, the scans that met the inclusion criteria were 55 scans.

\subsection{Data Collection}

Each of the scans was evaluated by the Investigator under standardised conditions from a computer screen. The septa presence, orientation, height and extent of the sinus, digital measurement of the height was done using the software. Also, the apicoantral distance between the floor of the sinus and maxillary teeth root tips was digitally measured by the software. The findings were recorded on a custom morphometry chart.

Volume determination was done via geometric calculation method according to the geometrical equation; where the Volume of the pyramid = Base Surface Area $\times 1 / 3$ Height.

Hence, volume of maxillary sinus (Pyramid) $=$ maximal anteroposterior width $(\mathrm{mm}) \times$ maximal craniocaudal length $(\mathrm{mm}) \times$ mediolateral(height)/ 3 .

In order to obtain the width, length, and height of the sinus, the coronal and axial cuts were sequentially reviewed to get maximum height of the sinus [mediolateral dimension] and the sagittal cuts were sequentially reviewed to get the maximum sinus base width [anteroposterior dimension] and length [craniocaudal dimension](Hamdy \& Abdel-Wahed, 2014) 


\subsection{Data Analysis}

The collected data was analyzed using IBM Statistical package for social sciences, SPSS version 23.0 and the information obtained was presented using descriptive statistics, graphs and pie charts were used to illustrate the data in diagrammatic format and relationships were tested using Independent Samples T-tests, Fisher's exact test, Pearson Chi Square tests, all tests at a $p$-value at $\leq 0.05$.

Ethical approval was sought and obtained from Kenyatta National Hospital-University of Nairobi Ethics and Research Committee (KNH-UoN ERC) Ref U885/ 11/ 2016. Permission was obtained from Dental and Maxillofacial Imaging Center (DAMIC) to use their radiographic records. All information was handled with utmost confidentiality and accuracy with access of the data restricted to the research team only.

\section{Results}

Out of the 55 CBCT scans, 20 scans (36.4\%) were of males and 35 scans (63.6\%) were of females. However, age was not available in the records of the scans.

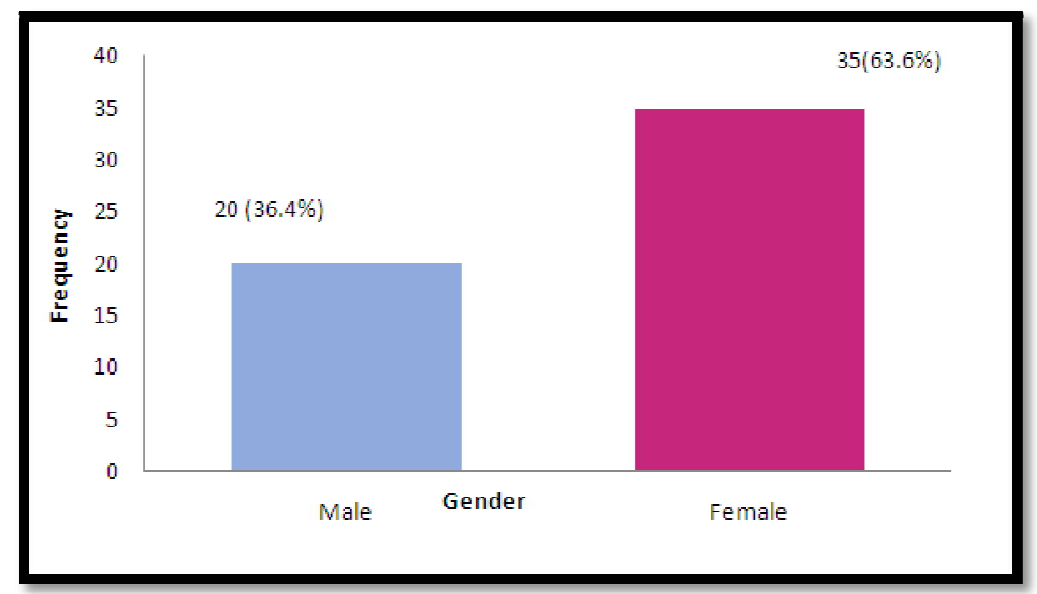

Figure 2: Gender Distribution

28 scans were of the left sinus while 27 scans were of the right sinus. In terms of view, 22 scans (40.0\%) were complete views showing all three dimensions while 33 scans $(60.0 \%)$ were incomplete having truncated craniocaudal (length) dimensions. All scans showed normal level of development i.e. there were no hypoplastic or absent sinuses.

Regarding the dental state of the upper arches scanned, 5 scans (9.1\%) were of edentulous upper ridges, while 50 scans $(90.9 \%)$ were of dentate ridges.

\subsection{Prevalence of Septation and Exostosis}

Out of the sinuses inspected for bony septa and exostoses, it was found that septa were present in 21 scans (38.2\%) and exostoses were present in $7(12.7 \%)$ of the sinuses.

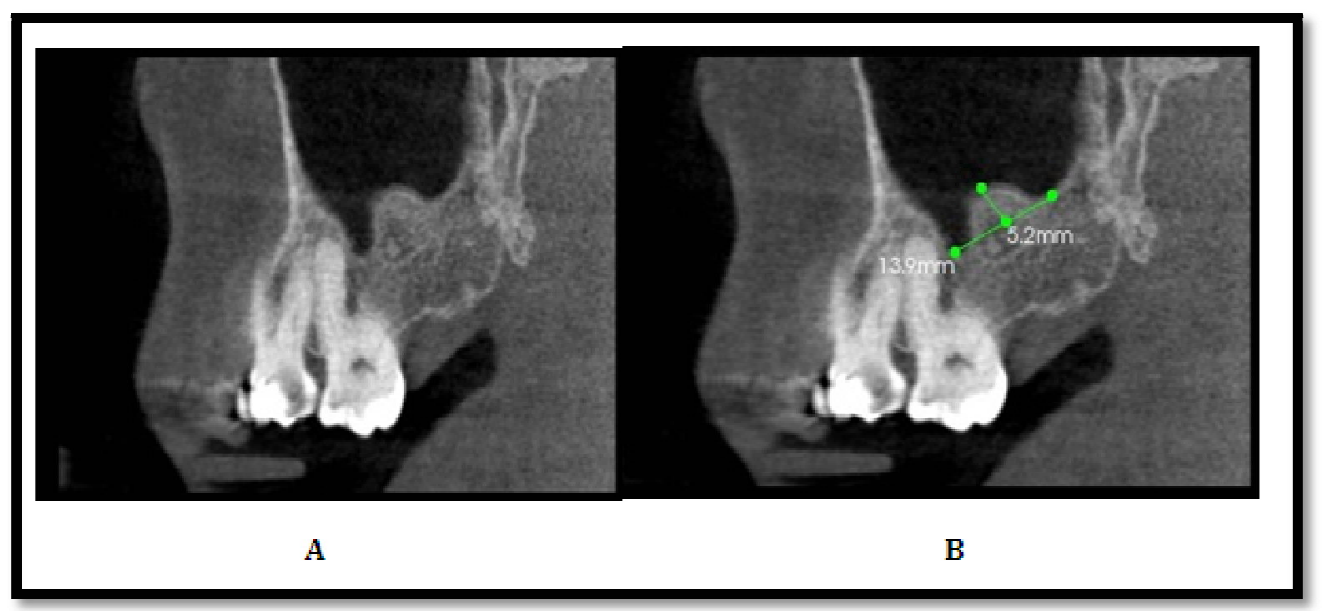

Figure 3: Sagittal Views of 2CBCT scans. (A) Rounded Bony Exostosis (B) The Measured Height of the Same Exostosis 


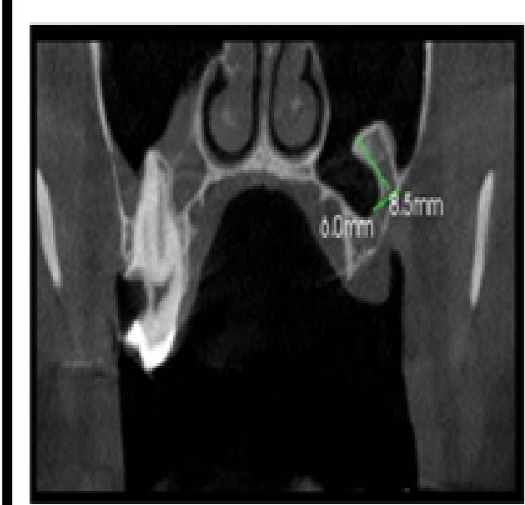

C

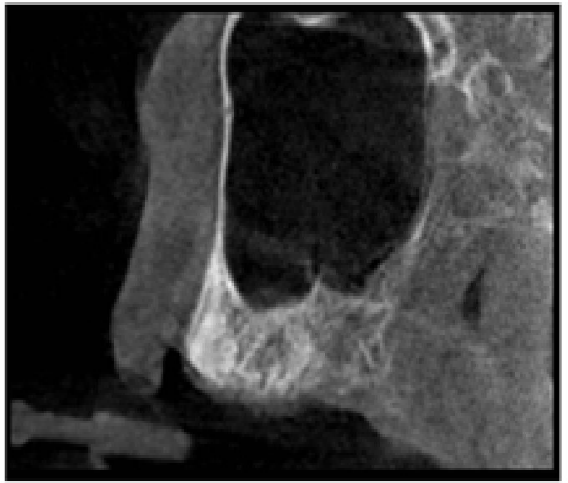

D

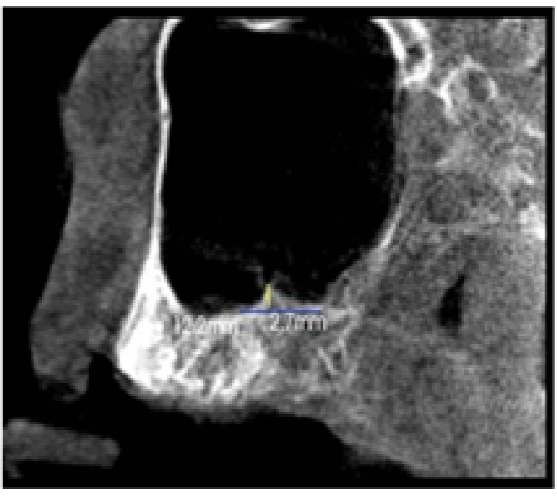

E

Figure 4: (C) Measured Bony Exostosis: Coronal Slice(D) Bony Septum In An ]Edentulous Participant.(E) The Measured Height Of The Same Septum

Only 3 scans had both exostosis and septa together. In terms of number of septa, 34(61.8\%) of the scans didn't have any, and $17(30.9 \%)$ had one septa while two septa were seen in 4(7.3\%) scans. Regarding the number of exostosis, 49(89.1\%) scans had none, 5 (9.1\%) sinuses had a single exostosis and only $1(1.8 \%)$ sinus had 2 exostoses.

Fisher's exact test was used to compare gender versus presence of septa and exostoses. Analysis showed the was no statistical difference; with septation $(\mathrm{p}=0.57)$ and exostosis. $(\mathrm{p}=1.00)$

\begin{tabular}{|c|c|c|c|c|}
\hline & & $\begin{array}{c}\text { Male } \\
\mathbf{N}(\mathbf{\%})\end{array}$ & $\begin{array}{c}\text { Female } \\
\mathbf{N}(\mathbf{\%})\end{array}$ & Fisher's Exact Test \\
\hline \multirow{2}{*}{ Septa } & Present & 9 & 12 & $\mathrm{p}=0.57$ \\
\cline { 2 - 4 } & Absent & 11 & 23 & \\
\hline \multirow{2}{*}{ Exostosis } & Present & 2 & 5 & $\mathrm{p}=1.00$ \\
\cline { 2 - 4 } & Absent & 18 & 30 & \\
\hline
\end{tabular}

Table 1: Distribution of Septa and Exostoses

In terms of location, 3(5.7\%) sinuses had septa on the anterior wall, 18(34.0\%) sinuses had septa on the floor and only $1(1.9 \%)$ had a bony septum on the posterior wall.

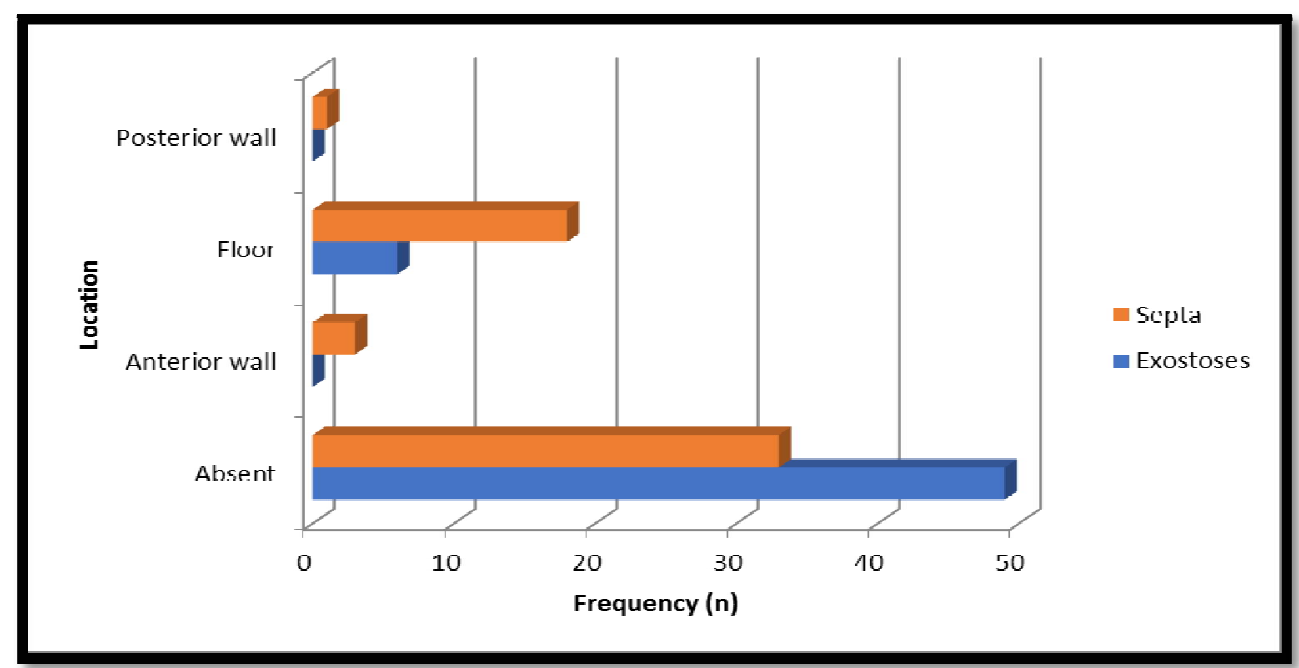

Figure 5: Distribution of Septa and Exostoses According to Location

The mean height of solitary bony septa was found to be $4.5 \mathrm{~mm} \pm 1.9 \mathrm{~mm}$. The mean height of septa seen in sinuses with dual septa was $3.3 \mathrm{~mm} \pm 1.0 \mathrm{~mm}$. The mean height of exostoses calculated as $4.2 \mathrm{~mm} \pm 2.2 \mathrm{~mm}$. 


\begin{tabular}{|c|c|c|c|}
\hline $\begin{array}{c}\text { Maxillary Posterior } \\
\text { Teeth }\end{array}$ & $\begin{array}{c}\text { Number Of Teeth } \\
\text { N (\%) }\end{array}$ & \multicolumn{2}{|c|}{ Mean Apicoantral Distance(Mm) \pm SD } \\
\hline Third molar & $19(15.2 \%)$ & Palatal root & $3.1 \pm 2.6$ \\
\cline { 3 - 4 } & & Buccal root & $2.3 \pm 1.7$ \\
\hline Second permanent molar & \multirow{2}{*}{$36(28.8 \%)$} & Palatal root & $2.7 \pm 1.8$ \\
\cline { 3 - 4 } & & Mesiobuccal root & $2.2 \pm 1.5$ \\
\cline { 3 - 4 } & \multirow{3}{*}{$36(28.8 \%)$} & Distobuccal root & $2.5 \pm 1.7$ \\
\cline { 3 - 4 } & & Pesiobulal root & $2.6 \pm 2.9$ \\
\cline { 3 - 4 } & & $\begin{array}{c}\text { Distobuccal rot } \\
\text { root }\end{array}$ & $2.7 \pm 2.1$ \\
\cline { 3 - 4 } & & Palatal root & $2.6 \pm 1.9$ \\
\cline { 3 - 4 } $\begin{array}{c}\text { Second premolar: two- } \\
\text { rooted }\end{array}$ & $9(7.2 \%)$ & Buccal root & $3.4 \pm 2.0$ \\
\hline $\begin{array}{c}\text { Second premolar: single } \\
\text { root }\end{array}$ & $25(20.0 \%)$ & Single root & $3.8 \pm 2.9$ \\
\hline Total & $125(100.0 \%)$ & & \\
\hline
\end{tabular}

Table 2: Distribution of the Apicoantral Distances of the Maxillary Posterior Teeth

A total of 125 teeth were analysed to obtain the Apicoantral(AA) distance. These teeth included, maxillary third molars, maxillary second permanent molars, maxillary first permanent molars and maxillary second premolars. Associated third molars were 19(15.2\%), second molars were 36(28.8\%), 36 first molars (28.8\%), 9 two-rooted second premolars and 25 second premolars (20\%) were single-rooted.

The closest root to the was the mesiobuccal root of the second permanent molar (mean distance: $2.2 \mathrm{~mm} \pm 1.5 \mathrm{~mm}$. The farthest root from the sinus floor from the teeth analysed was the second premolar: single-rooted followed by the palatal root of the two-rooted second premolar.

\begin{tabular}{|c|c|c|c|}
\hline \multirow{2}{*}{ Root of 2nd Molar } & Gender & $\begin{array}{c}\text { Apicoantral Distance } \\
\text { (Mm } \pm \text { SD) }\end{array}$ & $\begin{array}{c}\text { Independent } \\
\text { Samples T-Test }\end{array}$ \\
\hline \multirow{2}{*}{ Palatal } & Male & $1.9 \pm 1.0$ & $\mathrm{p}=0.4$ \\
\cline { 2 - 3 } & Female & $2.3 \pm 2.0$ & \\
\hline \multirow{2}{*}{ Mesio-buccal } & Male & $1.3 \pm 0.5$ & $\mathrm{p}=0.04$ \\
\cline { 2 - 3 } & Female & $2.0 \pm 1.6$ & \\
\hline \multirow{2}{*}{ Disto-buccal } & Male & $1.6 \pm 1.0$ & $\mathrm{p}=0.2$ \\
\cline { 2 - 3 } & Female & $2.2 \pm 1.8$ & \\
\hline
\end{tabular}

Table 3: T-Test for the Second Molar versus Gender

There was a statistically significant difference between gender and the mesiobuccal root apicoantral distance of the second permanent molar.

\subsection{Maxillary Sinus Dimensions}

The dimensions measured include: maximal anteroposterior distance (width of the triangular shaped sinus), maximal craniocaudal distance (length of the sinus) and the maximal mediolateral distance(height). For the anteroposterior and mediolateral dimensions, all 55 sinuses offered complete view, while the craniocaudal distance was complete in only 23 instances (41.8\%). The mean Anteroposterior length was $37.9 \mathrm{~mm} \pm 4.1 \mathrm{~mm}$. The mean Craniocaudal length was $32.6 \mathrm{~mm} \pm 4.0 \mathrm{~mm}$ while the mean mediolateral dimension was $27.5 \mathrm{~mm} \pm 5.0 \mathrm{~mm}$. The breakdown according to gender is in the table below. There was statistically significant difference between gender and the anteroposterior distance $(p=0.02)$.

\begin{tabular}{|c|c|c|c|c|}
\hline Dimension & Gender & $\begin{array}{c}\text { Number of } \\
\text { individuals, N(\%) }\end{array}$ & $\begin{array}{c}\text { Mean } \\
\text { length(mm) }\end{array}$ & \multirow{2}{*}{ Level of confidence } \\
\hline Maximal & Male & $20(36.4 \%)$ & $39.5 \pm 3.9$ & \multirow{2}{*}{$\mathrm{P}=0.02$} \\
\cline { 2 - 4 } AP(width) & Female & $35(63.6 \%)$ & $36.9 \pm 4.0$ & \multirow{2}{*}{$\mathrm{P}=0.16$} \\
\hline Maximal & Male & $13(56.5 \%)$ & $33.7 \pm 4.8$ & \multirow{2}{*}{$\mathrm{P}=0.17$} \\
\cline { 2 - 4 } CC(length) & Female & $10(43.5 \%)$ & $31.2 \pm 2.1$ & $28.8 \pm 4.9$ \\
\hline Maximal & Male & $20(36.4 \%)$ & $26.8 \pm 5.0$ & \\
\cline { 2 - 5 } ML(height) & Female & $35(63.6 \%)$ & \multicolumn{2}{|c}{}
\end{tabular}

Table 4: Dimensions of the Sinus with Respect to Gender 


\subsection{Sinus Volume}

Out of the 55 sinuses analysed, only $23(41.8 \%)$ had complete volumes. The mean volume was $12,634.9 \pm 4549.7 \mathrm{~mm}^{3}$ $(12.6 \pm 4.6 \mathrm{ml})$. Out of the 23 complete sinuses, the average sinus volume for $13(23.6 \%)$ scans of males was $13,980.4 \pm 5024.4 \mathrm{~mm}^{3}(13.9 \pm 5.2 \mathrm{ml})$, while in ten $(18.2 \%)$ females the sinus volume was $10,885.8 \pm 3305.6 \mathrm{~mm}^{3}$ $(10.9 \pm 3.3 \mathrm{ml})$. The sinus volume was greater in the males; however, the differences in the volume was non-significant with an independent samples t- test with a Levene, $\mathrm{p}=0.27$ at 95\% CL.

\section{Discussion}

The choice of CBCT over conventional panoramic radiograph in order to avoid disadvantages such as superimposition of anatomic structures, lack of cross-sectional information and horizontal and vertical magnification that are associated with panoramic radiographs.

The gender distribution of the sinuses evaluated was uneven with a Male to female ratio at1:1.75. This ratio was similar to an Iranian population study that had a 1:1.85 ratio (Shahidi et al., 2016). However, the gender ratio is not in line with the 2009 Kenyan population census and a Turkish study by Orhan et al., which reported a male to female ratio of 1:1.01("Kenya National Census,2009," n.d.) and 1:1.27(Orhan et al., 2013) respectively.This could be due to females having a more positive health seeking behavior compared to males. Age comparisons could not be made due to lack of documentation of age in the digital records.

Out of the sinuses evaluated, $50.9 \%$ were of the left side while $49.1 \%$ were those of the right side. This statistic is close to that of a study by Orhan et al. that showed the left sinuses constituting $55 \%$ while $44.9 \%$ were of the right side(Orhan et al., 2013). This study showed that $9.1 \%$ were edentulous, $90.1 \%$ were dentate. The participants were in either partially dentate and edentulous. The primary major indication for the CBCT scans is for ridge analysis as part of implant planning. This low turnout in edentulous participants is contrary to what would be expected; edentulous patients lacking teeth would need implants than dentate patients. This can be attributed to edentulous cases requiring multiple implants thus more expensive compared to singular implants in partially dentate individuals. It can also be attributed to the fact that partial dentate being more common than edentulism.

\subsection{Presence of Septa and Exostosis}

This study showed that bony septa in the sinus was present in $37.5 \%$ of the sinuses evaluated while exostoses were found to be $12.7 \%$. A majority of the septa were located on the floor of the sinus projecting superiorly (32.7\%) with the least being on the posterior wall (1.8\%). This shows that since most septa are found on the floor, chances of perforations are higher. This in turn emphasizes the need for diagnostic CBCT scans of the para-antral area before any implant surgeries in the posterior maxillary area(Eberhardt et al., 1992). The mean height of the septa was $4.5 \pm 1.9 \mathrm{~mm}$. The reported prevalence conforms to that of a similar study done in South Korea showed that prevalence of septation as $31.76 \%$ with the mean septal height being $5.5 \pm 3.1 \mathrm{~mm}$ (Kim et al., 2006). Another study done in a Spanish population showed the prevalence of septation as 25\%.("A Study of the Septa in the Maxillary Sinuses and the Subantral Alveolar Processes in 30 Patients | Journal of Oral Implantology," n.d.) This difference can be attributed to anatomical variations between different populations. Also, due to lack of statistically significant difference between gender and prevalence of septation ( $p>0.05$ ), it concluded that there was no association between gender and presence of septa and exostoses.

\subsection{Apicoantral Distances}

The closest root apex to the floor of the sinus was found to be the mesiobuccal root of the second permanent maxillary molar with a mean of $2.2 \pm 1.5 \mathrm{~mm}$, while the farthest root tip being that of the single-rooted second maxillary premolar with a mean of $3.8 \pm 2.9 \mathrm{~mm}$. A study done by Eberhardt et al. (Eberhardt et al., 1992) demonstrated using CT scans and supported the finding that the closest root was the mesiobuccal root apex of the second molar as was seen in the current study, while a study in a Turkish population by Kilic et al. (Kilic et al., 2010) concluded that the distobuccal root tip of the second molar was closest to the floor of the sinus. This reiterates the fact that the closest roots to the sinus are those of the molars while those farthest among the teeth aligning with the anterior border of the sinus, are the premolars. Several studies have investigated the maxillary sinus dimensions, volume and relative distances between teeth and the sinus(13,25-27).The measured complete craniocaudal length had a mean of $32.64 \pm 4.01 \mathrm{~mm}$. This falls close to the craniocaudal mean distance in a study by Hamdy and Abdel-Wahed(Hamdy \& Abdel-Wahed, 2014) in an Egyptian population with a mean $35.54 \pm 3.96 \mathrm{~mm}$. Using an independent samples T-test, there was no relationship determined between gender and the craniocaudal length.

The mean AP distance was $37.89 \pm 4.13 \mathrm{~mm}$. Gender was associated with the anteroposterior distance of the sinus $(\mathrm{p}<0.05)$. The mean mediolateral distance was $27.5 \pm 5.0 \mathrm{~mm}$. The mediolateral distance was not associated with gender. The study done in Cairo by Hamdy and Abdel-Wahed has similar figures to those of this study: mean AP: $31.5 \pm 3.2 \mathrm{~mm}$ and mean ML distance: $20.4 \pm 2.6 \mathrm{~mm}$. (Hamdy \& Abdel-Wahed, 2014) This goes to show that little interpopulation variation exists with dimensions being almost similar. The mean volume of the sinus in males in a Kenyan population was found to be $13980.4 \pm 5024.4 \mathrm{~mm}^{3}(13.9 \pm 5.2 \mathrm{mls})$ and females being $10,885.8 \pm 3,305.6 \mathrm{~mm}^{3}(10.9 \pm 3.3 \mathrm{mls})$. This shows sinus volumes in males being larger than in females. Furthermore, there was no association ( $p>0.05)$ between gender and the sinus volume. Sharah and Madjar (Sharan \& Madjar, 2008) observed post-extraction pneumatization of the maxillary sinus following extraction of posterior maxillary teeth. This phenomenon results from an inferior displacement of the floor of the sinus thereby increasing maxillary sinus volume. Additionally, the study recommended that to prevent the inferior shift of the sinus floor above an extraction site, immediate implant placement and/ or immediate bone grafting should be done. 


\section{Conclusions}

The incidence of septation, inter and intra-person anatomic variation, the sinus volume and the apicoantral dimensions of the maxillary sinus were observed in a third of the study population. The closest tooth to the sinus was the second permanent molar, specifically the mesiobuccal root while the farthest tooth was the single-rooted second premolar. The sinus dimensions in both genders were the same except for the anteroposterior length.

Study Challenges: There were inadequate CBCT scans with full extent of both maxillary sinuses and which met the study criteria. Finance and time were also constraints at the time of the study.

Conflict of interest: We have no conflict of interest.

\section{References}

i. Al-Dajani, M. (2016). Incidence, Risk Factors, and Complications of Schneiderian Membrane Perforation in Sinus Lift Surgery: A Meta-Analysis. Implant Dentistry, 25(3), 409-415. https:/ / doi.org/ 10.1097/ ID.0000000000000411

ii. Ariji, Y., Ariji, E., Yoshiura, K., \& Kanda, S. (1996). Computed tomographic indices for maxillary sinus size in comparison with the sinus volume. Dentomaxillofacial Radiology, 25(1), 19-24. https:/ / doi.org/ 10.1259/ dmfr.25.1.9084281

iii. A Study of the Septa in the Maxillary Sinuses and the Subantral Alveolar Processes in 30 Patients | Journal of Oral Implantology. (n.d.). Retrieved September 3, 2016, from http:// www.joionline.org/ doi/ 10.1563/ 15481336\%282007\%2933\%5B340:ASOTSI\%5D2.0.CO;2?url ver=Z39.88-

2003\&rfr_id=ori\%3Arid\%3Acrossref.org\&rfr_dat=cr_pub\%3Dpubmed\&

iv. Basic Principles of Cone Beam Computed Tomography. (n.d.). Retrieved September 10, 2016, from http:/ / www.sciencedirect.com/ science/ article/ pii/ S0011853214000263

v. Eberhardt, J. A., Torabinejad, M., \& Christiansen, E. L. (1992). A computed to mographic study of the distances between the maxillary sinus floor and the apices of the maxillary posterior teeth. Oral Surgery, Oral Medicine, Oral Pathology, 73(3), 345-347. https:/ / doi.org/ 10.1016/ 0030-4220(92)90133-B

vi. Hamdy, R. M., \& Abdel-Wahed, N. (2014). Three-dimensional linear and volumetric analysis of maxillary sinus pneumatization. Journal of Advanced Research, 5(3), 387-395. https:/ / doi.org/ 10.1016/ j.jare.2013.06.006

vii. Hauman, C. H. J., Chandler, N. P., \& Tong, D. C. (2002). Endodontic implications of the maxillary sinus: a review. International Endodontic Journal, 35(2), 127-141. https:/ / doi.org/ 10.1046/ j.0143-2885.2001.00524.x

viii. Jun, B.-C., Song, S.-W., Park, C.-S., Lee, D.-H., Cho, K.-J., \& Cho, J.-H. (2005). The analysis of maxillary sinus aeration according to aging process; volume assessment by 3-dimensional reconstruction by high-resolutional CT scanning. Otolaryngology -- Head and Neck Surgery, 132(3), 429-434.

https:/ / doi.org/ 10.1016/ j.otohns.2004.11.012

ix. Kenya National Census, 2009. (n.d.).

x. Kilic, C., Kamburoglu, K., Yuksel, S. P., \& Ozen, T. (2010). An Assessment of the Relationship between the Maxillary Sinus Floor and the Maxillary Posterior Teeth Root Tips Using Dental Cone-beam Computerized Tomography. European Journal of Dentistry, 4(4), 462-467.

xi. Kim, M.-J., Jung, U.-W., Kim, C.-S., Kim, K.-D., Choi, S.-H., Kim, C.-K, \& Cho, K.-S. (2006). Maxillary sinus septa: prevalence, height, location, and morphology. A re-formatted computed tomography scan analysis. Journal of Periodontology, 77(5), 903-908. https:/ / doi.org/ 10.1902/ jop.2006.050247

xii. Koymen, R., Gocmen-Mas, N., Karacayli, U., Ortakoglu, K., Ozen, T., \& Yazici, A. C. (2009). Anatomic evaluation of maxillary sinus septa: surgery and radiology. Clinical Anatomy (New York, N.Y.), 22(5), 563-570. https:/ / doi.org/ 10.1002/ ca.20813

xiii. Krennmair, G., Ulm, C. W., Lugmayr, H., \& Solar, P. (1999). The incidence, location, and height of maxillary sinus septa in the edentulous and dentate maxilla. Journal of Oral and Maxillofacial Surgery: Official Journal of the American Association of Oral and Maxillofacial Surgeons, 57(6), 667-671; discussion 671-672.

xiv. Neugebauer, J., Ritter, L., Mischkowski, R. A., Dreiseidler, T., Scherer, P., Ketterle, M., ... Zöller, J. E. (2010). Evaluation of maxillary sinus anatomy by cone-beam CT prior to sinus floor elevation. The International Journal of Oral \& Maxillofacial Implants, 25(2), 258-265.

xv. Ochola S., Muasya M, Hassanali J, \& Guthua S.W. (2001). Radiographic Analysis of Size and Pattern of Maxillary and Frontal air Sinuses in Kenyan Adults. African Journal of Oral Health Sciences, Vol 3(No. 3). Retrieved from https:/ / profiles.uonbi.ac.ke/ jali/ publications/ ochola-s-muasya-m-hassanali-j-guthua-sw-radiographic-analysissize-and-pattern-max

xvi. Orhan, K., Kusakci Seker, B., Aksoy, S., Bayindir, H., Berberoglu, A., \& Seker, E. (2013). Cone Beam CT Evaluation of Maxillary Sinus Septa Prevalence, Height, Location and Morphology in Children and an Adult Population. Medical Principles and Practice, 22(1), 47-53. https:/ / doi.org/ 10.1159/000339849

xvii. Paranasal Sinus Anatomy: Overview, Gross Anatomy, Microscopic Anatomy. (2016). Retrieved from http:/ / emedicine.medscape.com/ article/ 1899145-overview

xviii. Sadler, T W. (2000). Head and Neck: Paranasal Air Sinuses. In Langman's Medical Embryology (8th ed., p. 395). LWW.

xix. Sandring, S, \& Berkovitz, Barry B (Eds.). (2004). Maxillary sinus. In Gray's Anatomy: The anatomical basis of clinical practice (39th ed., pp. 576-578). Elsevier Churchill Livingstone. 
xx. Scarfe William C., Farman Allan G., \& Sukovic Predag. (n.d.). Clinical Applications of Cone-Beam Computed Tomography in Dental Practice. Retrieved September 7, 2016, from http:// www.cda-adc.ca/jcda/ vol-72/ issue1/ 75.html

xxi. Shahidi, S., Zamiri, B., Momeni Danaei, S., Salehi, S., \& Hamedani, S. (2016). Evaluation of Anatomic Variations in Maxillary Sinus with the Aid of Cone Beam Computed Tomography (CBCT) in a Population in South of Iran. Journal of Dentistry (Shīrāz, Iran), 17(1), 7-15.

xxii. Sharan, A., \& Madjar, D. (2008). Maxillary sinus pneumatization following extractions: a radiographic study. The International Journal of Oral \& Maxillofacial Implants, 23(1), 48-56.

xxiii. Tihomir Georgiev, Karen Djabalian, Radosveta Andreeva, \& Krasimira Prodanova. (2016). LINEAR AND VOLUMETRIC ASSESSMENT OF THE MAXILLARY SINUS. Scripta Scientifica Medicinae Dentalis, Vol 2(No. 1), pp 62-69.

xxiv. Ulm, C. W., Solar, P., Krennmair, G., Matejka, M., \& Watzek, G. (1995). Incidence and suggested surgical management of septa in sinus-lift procedures. The International Journal of Oral \& Maxillofacial Implants, 10(4), 462-465.

xxv. Underwood, A. S. (1910). An Inquiry into the Anatomy and Pathology of the Maxillary Sinus. Journal of Anatomy and Physiology, 44(Pt 4), 354-369.

xxvi. Velásquez-Plata, D., Hovey, L. R., Peach, C. C., \& Alder, M. E. (2002). Maxillary sinus septa: a 3-dimensional computerized tomographic scan analysis. The International Journal of Oral \& Maxillofacial Implants, 17(6), 854860. 